Voix et Images

voixetimages

\title{
Table des matières du volume $X$
}

Volume 10, numéro 3, printemps 1985

André Major

URI : https://id.erudit.org/iderudit/200531ar

DOI : https://doi.org/10.7202/200531ar

Aller au sommaire du numéro

Éditeur(s)

Université du Québec à Montréal

\section{ISSN}

0318-9201 (imprimé)

1705-933X (numérique)

Découvrir la revue

Citer ce document

(1985). Table des matières du volume X. Voix et Images, 10(3), 227-229.

https://doi.org/10.7202/200531ar d'utilisation que vous pouvez consulter en ligne.

https://apropos.erudit.org/fr/usagers/politique-dutilisation/ 


\section{Table des matières du volume $X$}

ALEXANDRE, Annie: «Albert Laberge: aux bords de l'ombre vague», 3, pp. 93-112

ANDERSON, M. Jean: «Fuir pour survivre: aliénation et identite chez Michèle Mailhot», 1, pp. 93-105.

ANDRÈS, Bernard: «Les mille et une scène de Rönfard», 1, pp. 177-178; «L'inceste en scène», 2, pp. 211-214.

BAYARD, Caroline: «Post-moderniste et avant-garde au Canada, 1960-1984», 1, pp. 37-58.

BEAUSOLEIL, Claude: «BJ/NBJ: un nouvel imaginaire», 2, pp. 167-171.

BELLEMARE, Yvon: «Jacques Godbout, diariste», 3, pp. 152-164

BISHOP, Neil: «L'univers poétique d'Anne Hébert», 2, pp. 207-209.

BLOUIN, Louise: «BJ/NBJ: fiction/théorie, postures ou impostures(?/!)» (en collaboration avec Bernard Pozier), 2, pp. 153-158.

BONENFANT, Joseph: «Des romans pour pas cher: la littérature de masse, sous le scalpel des universitaires" (en collaboration avec André Brochu et Gilles Marcotte), 1, pp. 131-133;

"Dossier: la BJ/NBJ, Présentation de la revue», 2, pp. 7-8; "Tableaux» (en collaboration avec André Gervais), 2, pp. 11-19; «Anthologie des politiques éditoriales de la BJ/NBJ» (en coll. avec A. Gervais), 2, pp. 21-66;

«Entrevues» (en coll. avec A. Gervais), 2, pp. 67-113;

«Bibliographie» (en coll. avec A. Gervais), 2, pp. 173-176;

«BJ/NBJ: petite réception en capsules» (en coll. avec A. Gervais), 2, pp. 177-185.

BOIVIN, Aurélien: «Bibliographie d'André Major», 3, pp. 70-89.

BROCHU, André: «Des romans pour pas cher: la littérature de masse, sous le scalpel des universitaires» (en collaboration avec Joseph Bonenfant et Gilles Marcotte), 1, pp. 134-136;

«Écriture en locomobile», 1, pp. 151-162;

«Un peu de tout», 2, pp. 189-199;

«Des fous et des autres», 3, pp. 179-187.

CARANI, Marie: «Rodolphe de Repentigny, critique d'art, théoricien et artiste», 3, pp. 137-151.

DUPRÉ, Louise: «BJ/NBJ: pour une lecture des politiques éditoriales», 2, pp. 115-124.

DUQUETTE, Jean-Pierre: "Lumières d'Espagne», 1, pp. 179-181.

ELDER, Jo-Anne: «Bibliographie sélective. Roman canadien», 1, pp. 63-65.

FRANCOLI, Yvette: «De l'autre côté du miroir... ou de la fenêtre», 3, pp. 201-203.

FRÉMONT, Gabrielle: «Le féminisme de la NBJ; un second souffle», 2, pp. 133-137. 
GAGNON, Claude-Marie: «Les éditions Édouard Garand et la culture populaire québécoise», 1, pp. 119-129.

GERVAIS, André: «Dossier: la BJ/NBJ. Présentation du dossier», 2, pp. 9-10;

"Tableaux" (en collaboration avec Joseph Bonenfant), 2, pp. 11-19; «Anthologie des politiques éditoriales de la BJ/NBJ» (en coll. avec $J$. Bonenfant), 2, pp. 21-66;

«Entrevues» (en coll. avec J. Bonenfant), 2, pp. 67-113;

«Bibliographie» (en coll. avec J. Bonenfant), 2, pp. 173-176;

«BJ/NBJ: petite réception en capsules» (en coll. avec J. Bonenfant), 2, pp. 177-185.

GIGUÈRE, Richard: «Une ou des littératures canadiennes? Une entrevue avec D.G. Jones», 1, pp. 5-22;

«Bibliographie sélective. Poésie canadienne», 1, pp. 59-62.

GILBERT LEWIS, Paula: «Trois générations des femmes: le reflet mèrefille dans quelques nouvelles de Gabrielle Roy», 3, pp. 165-176.

GRANDPRÉ, Chantale de: «Gaston Miron: le rythme, le sens, le sujet», 3, pp. 126-136.

HÉBERT, Pierre: «Gérard Bessette: l'Incubation et ses figures», 1, pp. 169-171.

JACQUES, Henri-Paul: «L'écriture: ultime recours, une entrevue avec André Major» (en collaboration avec Jacques Pelletier et André Vanasse) 3, pp. 12-21; "Parenthèse et exôthèse chez André Major», 3, pp. 34-69.

LAHAISE, Robert: Réginald Hamel, la Louisiane créole, 3, pp. 204-206.

LAPRISE, Jean: «La langue des Bois: le toponyme amérindien dans le roman québécois» (en collaboration avec Guildo Rousseau), 1, pp. 69-92.

LÉVESQUE, Gaëtan: «La revue des revues», 1, pp. 185-193; 2, pp. 221-227.

MALENFANT, Paul Chanel: «Coup de barre: sites d'une lecture», 2, pp. 139-151.

MARCOTTE, Gilles: «Des romans pour pas cher: la littérature de masse, sous le scalpel des universitaires» (en collaboration avec Joseph Bonenfant et André Brochu), 1, pp. 137-139.

MAJOR, André: «Préface», 3, pp. 5-11.

MELANÇON, Benoît: "Yves Thériault et l'Institution littéraire québécoise», 1, pp. 174-175;

«le Spectacle de la littérature», 2, pp. 205-206.

MICHON, Jacques: «le Phénomène IXE-13», 2, pp. 201-204;

«D'ailleurs et d'ici», 3, pp. 197-200.

NEPVEU, Pierre: «BJ/NBJ: difficile modernité», 2, pp. 159-165.

PELLETIER, Jacques: «L'Écriture: ultime recours, une entrevue avec André Major», (en collaboration avec Henri-Paul Jacques et André Vanasse), 3, pp. 12-21. 
POZIER, Bernard: «BJ/NBJ: fiction/théorie, postures ou impostures (?/!)» (en collaboration avec Louise Blouin), 2, pp. 153-158.

PURDY, Anthony: «De "L'art de la défaite" à Prochain Épisode: un récit unique», 3, pp. 113-125.

ROUSSEAU, Guildo: «La langue des bois: le toponyme amérindien dans le roman québécois» (en collaboration avec Jean Laprise), 1, pp. 69-92.

SABOURIN, Claude: «Les numéros «femmes» de la BJ/NBJ: pour une transformation des pratiques discursives», 2, pp. 125-132.

SABOURIN, Pierre: «La revue des revues», 3, pp. 209-214.

SAINT-JACQUES, Denis: "Faut voir ça» ou la Liberté dans la culture de masse», 1, pp. 141-147.

SAINT-MARTIN, Lori: «Mise à mort de la femme et «libération» de l'homme: Godbout, Aquin, Beaulieu», 1, pp. 107-117.

SMART, Patricia: «L'espace de nos fictions: quelques réflexions sur nos deux cultures», 1, pp. 23-36.

THÉRIEN, Gilles: «Mario ou l'apogée du cinéma québécois», 2, pp. 215-218.

VANASSE, André: «Le syndrome professoral», 1, pp. 163-167; «L'Écriture: ultime recours, une entrevue avec André Major», (en collaboration avec Henri-Paul Jacques et Jacques Pelletier), 3, pp. 12-21. «Méduse photographiée», 3, pp. 22-33.

VIGNEAULT, Robert: «Jean-Louis Major et l'exigence d'écriture», 3, pp. 188-196.

YERGEAU, Robert: «Alain Grandbois: le douloureux destin», 1, pp. 172-173. 